\title{
THE TORN ACETABULAR LABRUM
}

\author{
J. H. DORRELL. A. CATTERALL
}

\author{
From the Royal National Orthopaedic Hospital, Stanmore
}

\begin{abstract}
Eleven patients with tears of the acetabular labrum are discussed and the syndrome of the torn labrum is defined. In all cases the lesion was associated with acetabular dysplasia, and a constant early radiological sign was a cyst in the lateral aspect of the acetabulum. The diagnosis was confirmed by arthrography.

It is suggested that these tears are degenerative, occurring as a consequence of abnormal stresses imposed by the uncovered lateral portion of the femoral head. Once a tear is present a localised stress point occurs on the femoral head, leading rapidly to degenerative arthritis.
\end{abstract}

Whereas the torn meniscus is a common cause of mechanical symptoms in the knee, the torn acetabular labrum is not normally recognised as a cause of mechanical symptoms in the hip and it has received little attention in the literature. Harris. Bourne and Oh (1979) reported eight cases where an abnormally situated intra-articular labrum was associated with idiopathic osteoarthritis and suggested that the position of the labrum might be an aetiological factor; they did not. however, record any tears of the labrum and thought its intra-articular position was congenital. There have been two cases described of a torn labrum in association with irreducible traumatic posterior dislocation of the hip (Paterson 1957: Dameron 1959), and Altenberg (1977) reported acute tears of the labrum caused by falls in two elderly patients; these tears caused pain and, in one patient, may have contributed to degenerative changes in the articular cartilage. Grossbard (1981) described a torn labrum which caused mechanical pain in the hip of a 10-year-old boy with healed Perthes' disease.

The object of this present paper is to report the clinical and radiological features of a previously unrecognised syndrome. namely a torn acetabular labrum in association with acetabular dysplasia.

\section{PATIENTS}

Twelve hips in 11 patients are described in which acetabular dysplasia was associated with a tear of the acetabular labrum. All the patients were females: their ages ranged from 13 to 47 years. In two patients congenital

J. H. Dorrell. FRCS. Senior Registrar

Department of Orthopaedics. Royal Berkshire Hospital, London Road. Reading RGI 5AN. England

A. Catterall. MChir. FRCS. Consultant Orthopaedic Surgeon

Roval National Orthopaedic Hospital. 234 Great Portland Street. London WIN 6AD. England.

Requests for reprints should be sent to Mr A. Catterall.

(1) 1986 British Editorial Society of Bone and Joint Surgery $0301620 \times 86 \quad 3054 \$ 2.00$ dislocation of the hip had been diagnosed late (at 15 months and 2 years respectively) and, despite reduction and containment procedures, acetabular dysplasia had developed.

In one patient with bilateral acetabular dysplasia (Case 7) who presented with a painful right hip, a shelf procedure had been performed on the left hip five years previously: in another (Case 8) the acetabular dysplasia was associated with cerebral palsy. In the remaining patients the dysplasia was not associated with any underlying condition.

\section{FINDINGS}

These are summarised in Table $\mathrm{I}$.

Clinical. Pain. Six patients complained of mechanical pain localised to the hip joint and variously described as "clicking". "sharp" or "catching". This was superimposed on previous aching pain which was also present in most of the hips.

Physical signs. The lump sign of acetabular dysplasia described by Catterall (1982) was easily felt in four patients. This sign is an uncovered anterolateral segment of the femoral head observed as a palpable lump or fullness below and medial to the anterior superior iliac spine.

In four patients the combined movement of rotation with flexion produced a sharp mechanical pain or click. Radiographic. In all patients there was evidence of acetabular dysplasia together with a cyst in the lateral part of the roof of the acetabulum. In those patients with bilateral dysplasia a cyst was present only on the side of the torn labrum. In one patient (Case 5) an initial arthrogram appeared normal, but a second one two years later revealed a tear of the acetabular labrum together with a cyst. In Case 9 no cyst was present on the initial radiographs but one was seen to evolve in serial radiographs over the next six months.

Arthrography. This investigation confirmed the presence of a torn acetabular labrum in every patient. However, in two (Cases 5 and 11) the significance of the lesion was not recognised on the initial arthrogram. 

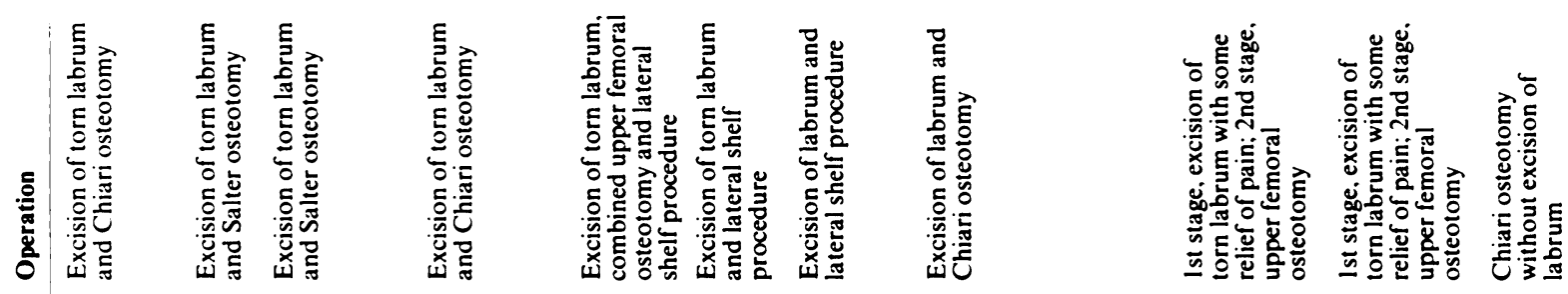

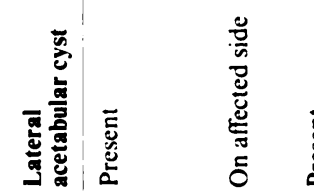
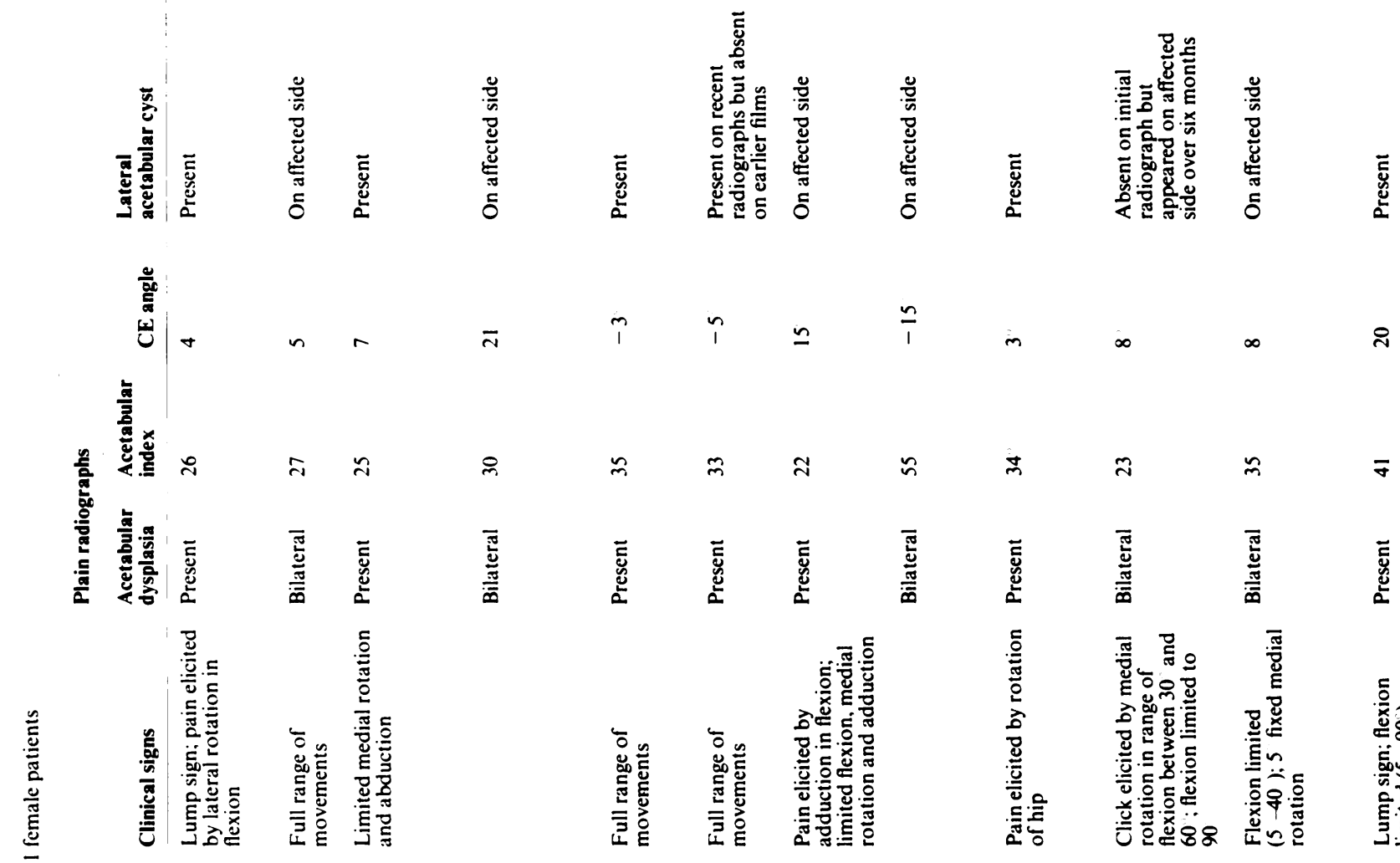

高

1)

$1 \frac{1}{1}$
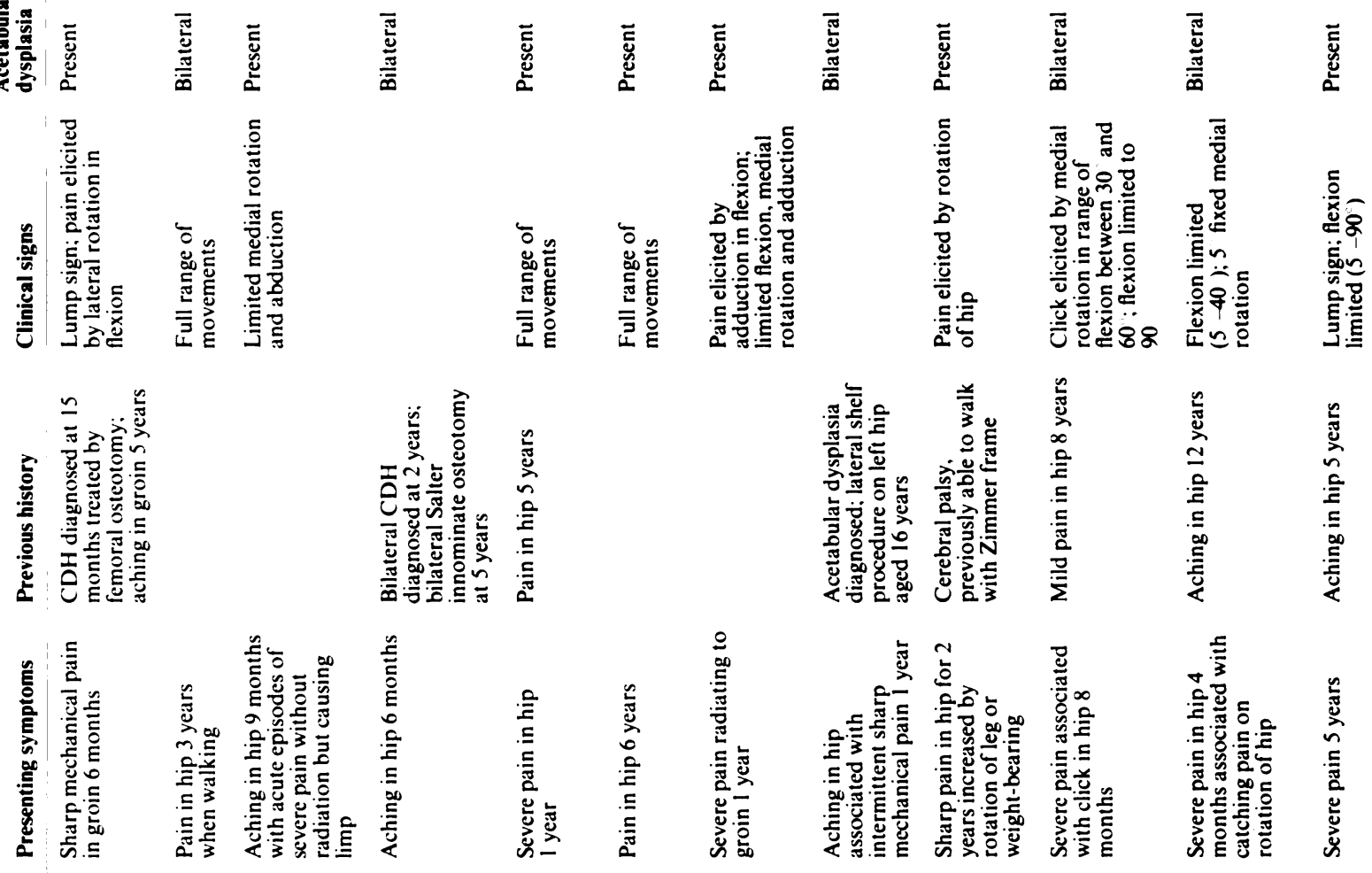

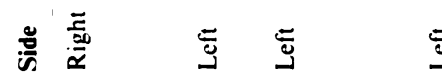

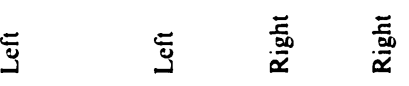

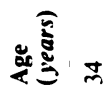

$m$ ก

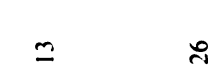

$\approx$

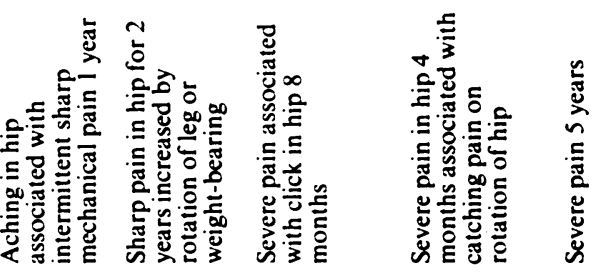

竞 


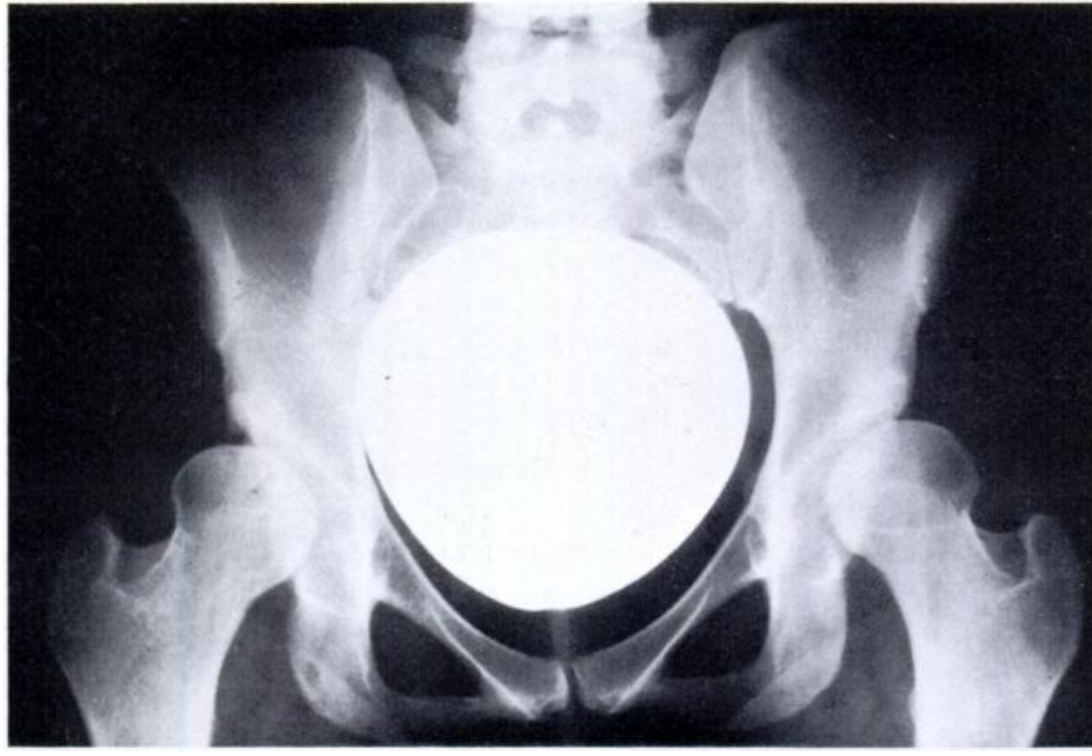

Fig. I

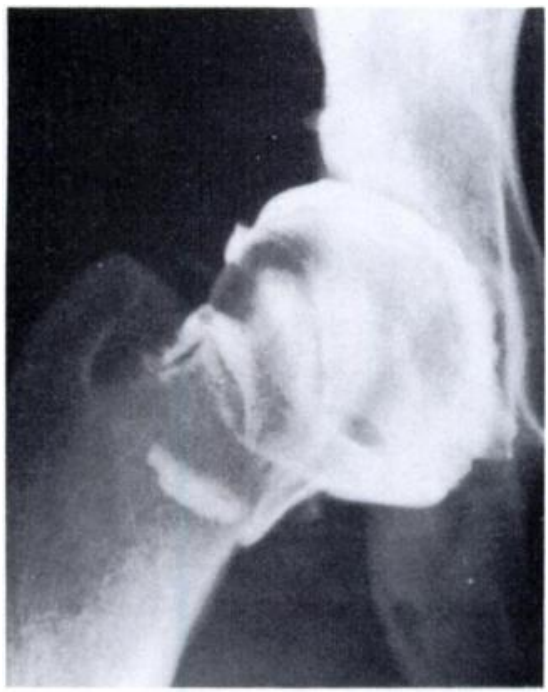

Fig. ?

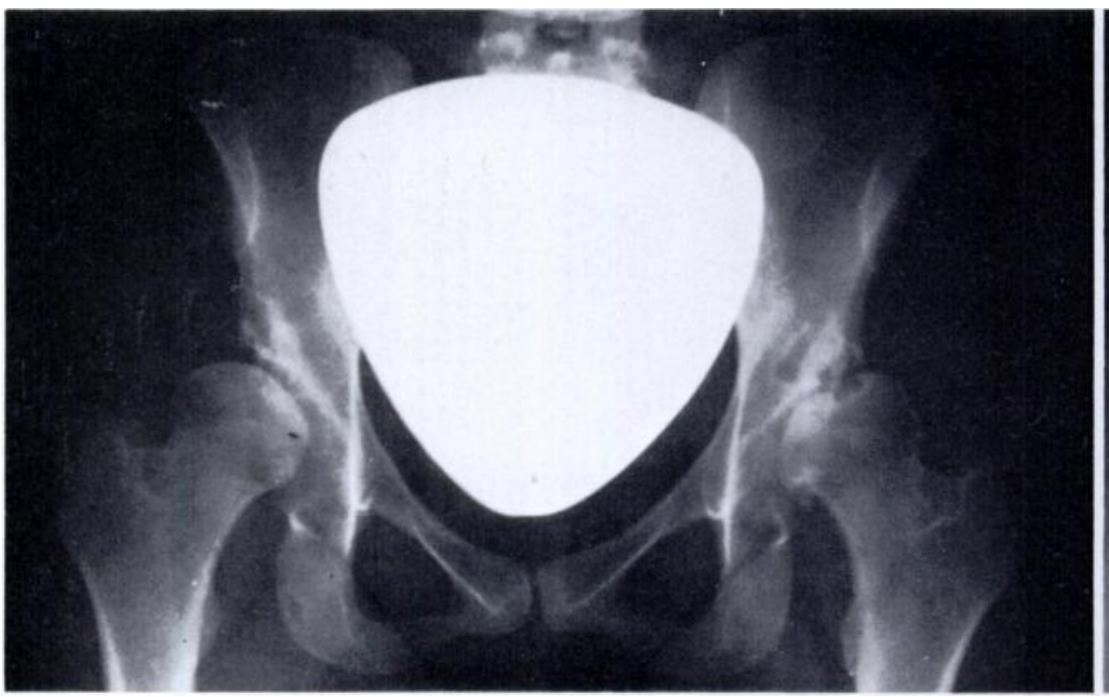

Fig. 4
Case 5

Figure $1-A$ radiograph taken at initial presentation show's bilateral acetabular dysplasia and a small cyst in the lateral part of the acetabular roof of the left hip. Figures 2 and 3-The initial arthrogram of the hips. In the right hip (Fig. 2) the labrum is intact: in the left (Fig. 3) it is torn. Figure 4-A radiograph two vears later shows that the osteoarthritis in the left hip has progressed and a cyst has developed on the right. Figure 5 An arthrogram of the right hip shows an established tear of the labrum in relation to the cyst in the lateral part of the acetabular roof.

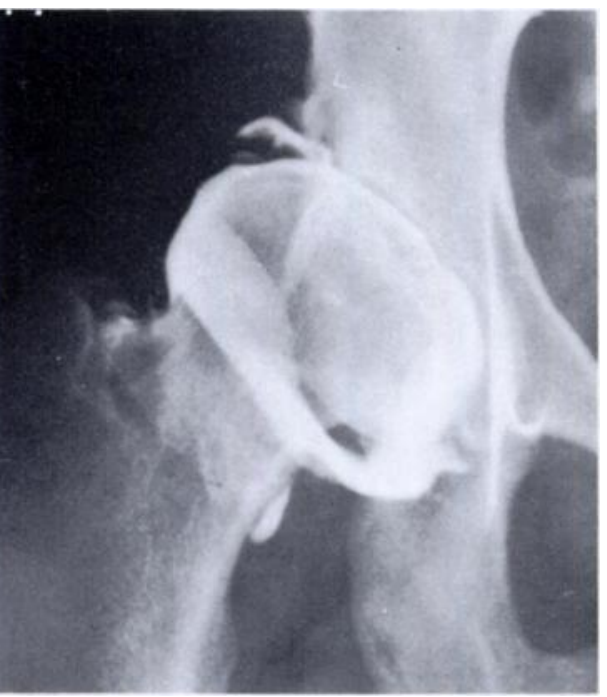

Fig. 5 
Operative. In all patients who had an arthrotomy a peripheral tear of the acetabular labrum was confirmed; the tear closely resembled a bucket-handle tear of the medial meniscus. In Cases 1 to 8 the torn labrum was excised, followed by a procedure designed to improve the cover of the femoral head. In Cases 9 and 10 only excision of the torn labrum was performed; in both of these there was incomplete relief of symptoms and a secondary procedure to improve cover was needed. In Case 11, the significance of the arthrographic finding was unrecognised and a Chiari procedure alone was performed; this failed to relieve the symptoms and there was rapid clinical and radiological deterioration during the next 18 months, and the patient finally needed a total hip replacement.

\section{CASE REPORT}

Case 5. A 26-year-old woman presented with bilateral hip pain, present for five years in the left hip (severe in the last year) and for six years in the right. Examination revealed a virtually full range of movement in both hips.

The initial radiograph showed bilateral acetabular dysplasia and a cyst in only the left lateral acetabular margin (Fig. 1). Arthrography (Figs 2 and 3) showed a normal right acetabular labrum but a torn acetabular labrum on the left: its significance was not recognised at that time.

The second radiograph and arthrogram taken two years later (Figs 4 and 5) revealed bilateral cysts and bilateral torn labra; in the left hip there were marked degenerative changes at the lateral acetabular margin. At operation the torn left labrum was excised and containment achieved by an upper femoral osteotomy and lateral shelf procedure. In the right hip the torn labrum was excised and containment achieved by an upper femoral osteotomy only.

\section{DISCUSSION}

A tear of the acetabular labrum should be suspected in patients who complain of either an acute exacerbation of pain or of sharp mechanical pain and clicking in a hip with acetabular dysplasia. The pain is usually described as "in the joint" rather than radiating to the groin and knee and in this respect differs from the aching typical of acetabular dysplasia. The clinical signs are variable but a "lump sign" may be present and pain or a click may be elicited on rotation and flexion movements of the hip. The constant radiological feature on plain radiographs is a cyst in the lateral margin of the acetabular roof in addition to the features of the underlying acetabular dysplasia. Serial radiographs usually show rapid progression of the osteoarthritis. Where a labral tear is suspected, an arthrogram combined with screening under an image intensifier will confirm the diagnosis.

We believe that these labral tears are not congenital: the lesion is an acquired one, as is the cyst in the acetabular roof. It would seem that the pre-existing dysplasia which has been relatively asymptomatic for a number of years may, because the femoral head is uncovered, lead to mechanical deformation of the cartilaginous tissues in the lateral part of the acetabulum. These tissues then become susceptible to degenerative damage in the same way as, in the older patient, the medial meniscus of the knee may develop a degenerative tear. Once a labral tear is present, there is loss of congruity between the femoral head and the acetabulum. with pressure-point loading of the femoral head and a rapidly progressive degenerative arthritis. If this progression is to be prevented the lesion must be diagnosed early and treated, not only by excision of the torn labrum but also by reconstructive surgery to improve congruity. In this respect the lesion previously reported by Harris et al. (1979) would seem to differ from the one we have described: their lesion is probably congenital and not associated with dysplasia, so that although excision of the labral tear may slow the progression of arthritis, reconstructive surgery is not needed. The lesion we describe is acquired and associated with acetabular dysplasia and both labral excision and reconstructive surgery are needed.

We are grateful to the Department of Medical Photography. St Mary`s Hospital, London for the preparation of the photographs.

\section{REFERENCES}

Altenberg AR. Acetabular labrum tears: a cause of hip pain and degenerative osteoarthritis. South Med J 1977;70:1745

Catterall A. Acetabular dysplasia. In: Tachdjian MO. ed. Congenital dislocation of the hip. Fdinburgh etc: Churchill Livingstone. 1982: 479501 .

Dameron TB. Bucket-handle tear of acetabular labrum accompanying posterior dislocation of the hip. J Bone Joint Surg [Am] 1959: $41 \mathrm{~A}: 1314$.

Grossbard GD. Hip pain during adolescence after Perthes disease. J Bone Joint Surg [Br] 1981:63 B:572 4.

Harris WH, Bourne RB, Oh I. Intra-articular acetabular labrum: a possible etiological factor in certain cases of osteoarthritis of the hip. J Bone Joint Surg [.Am] 1979:61 A:510 4.

Paterson I. The torn acetabular labrum: a block to reduction of a dis located hip. J Bome Joint Surg [Br] 1957:39 B:306 9. 